\title{
RITA enhances irradiation-induced apoptosis in p53-defective cervical cancer cells via upregulation of IRE1 $\alpha /$ XBP1 signaling
}

\author{
HONG ZHU ${ }^{1}$, MUYASHA ABULIMITI ${ }^{1}$, HUAN LIU ${ }^{1}$, XIANG-JIANG SU ${ }^{1}$, CAI-HONG LIU $^{1}$ and HAI-PING PEI ${ }^{2}$ \\ Departments of ${ }^{1}$ Oncology and ${ }^{2}$ Gastrointestinal Surgery, Xiangya Hospital, \\ Central South University, Changsha, Hunan 410008, P.R. China
}

Received March 11, 2015; Accepted May 29, 2015

DOI: $10.3892 /$ or.2015.4083

\begin{abstract}
Radiation therapy is the most widely used treatment for patients with cervical cancer. Recent studies have shown that endoplasmic reticulum (ER) stress induces apoptosis and sensitizes tumor cells to radiotherapy, which reportedly induces ER stress in cells. Classical key tumor suppressor p53 is involved in the response to a variety of cellular stresses, including those incurred by ionizing irradiation. A recent study demonstrated that small-molecule RITA (reactivation of p53 and induction of tumor cell apoptosis) increased the radiosensitivity of tumor cells expressing mutant p53 (mtp53). In the present study, we explored the effects and the underlying mechanisms of RITA in regards to the radiosensitivity and ER stress in mtp53-expressing human cervix cancer cells. Treatment with $1 \mu \mathrm{M}$ of RITA for $24 \mathrm{~h}$ before irradiation markedly decreased survival and increased apoptosis in C-33A and HT-3 cells; the effects were not significantly altered by knockdown of p53. In the irradiated C-33A and HT-3 cells, RITA significantly increased the expression of IRE1 $\alpha$, the spliced XBP1 mRNA level, as well as apoptosis; the effects were abolished by knockdown of IRE1 $\alpha$. Transcriptional pulse-chase assays revealed that RITA significantly increased the stability of IRE1 $\alpha$ mRNA in the irradiated C-33A and HT-3 cells. In contrast, the same RITA treatment did not show any significant effect on sham-irradiated cells. In conclusion, the present study provides initial evidence that RITA upregulates the expression level of IRE1 $\alpha$ by increasing the stability of IRE1 $\alpha$ mRNA in irradiated mtp53-expressing cervical cancer cells; the effect leads to enhanced IRE1 $\alpha /$ XBP1 ER stress signaling and increased apoptosis in the cells. The present study offers novel insight into the pharmacological potential of RITA in the radiotherapy for cervical cancer.
\end{abstract}

Correspondence to: Dr Hai-Ping Pei, Department of Gastrointestinal Surgery, Xiangya Hospital, Central South University, 87 Xiangya Road, Changsha, Hunan 410008, P.R. China

E-mail: peihaiping1966@163.com

Key words: RITA, cervical cancer, p53, endoplasmic reticulum stress, IRE1 $\alpha, \mathrm{XBP} 1$, apoptosis

\section{Introduction}

Cervical cancer is the second most common type of cancer in females, with $~ 530,000$ new cases each year and more than 274,000 mortalities worldwide (1). Since cervical cancer is considered a radiosensitive tumor, radiation therapy is the most widely used treatment modality in patients with cervical cancer, particularly for patients at an advanced stage or those who cannot be cured surgically (2). Therefore, cellular radiosensitivity has been a long-term research focus, for it is critical for therapeutic outcomes (3). However, despite progress in radiation technology, local recurrence still occurs in a large proportion of patients due to radioresistance (4). Thus, it is urgent to uncover new targets to enhance the cellular radiosensitivity in cervical cancer.

The endoplasmic reticulum (ER) is an essential subcellular compartment responsible for the synthesis and folding of proteins (5). Different physiological and pathological perturbations interfere with protein folding processes in the ER lumen, leading to accumulation of unfolded or misfolded proteins, a cellular condition termed ER stress (5). ER stress triggers the unfolded protein response (UPR), a transcriptional induction pathway aimed at restoring normal ER functioning (6). If UPR is insufficient to recover ER homeostasis, cells undergo apoptosis (5). The UPR is mediated by three ER stress receptors: protein kinase RNA-like ER kinase (PERK), inositol-requiring protein-1 (IRE1) and activating transcription factor-6 (ATF6), representing three branches of the UPR (7). In the IRE1 branch of UPR, activation of IRE1 leads to cleavage of a 26-nucleotide intron from the XBP1 mRNA. The spliced XBP1 mRNA encodes a stable, active transcription factor that binds to many UPR target genes $(8,9)$. Recent studies have shown that ER stress induces apoptosis and sensitizes tumor cells to ionizing radiation and chemotherapy (10-12), suggesting that ER stress has the potential as a novel target to improve cancer radiotherapy and chemotherapy. In addition, radiotherapy reportedly induces ER stress in cells (13).

Classical key tumor suppressor p53 is involved in the response to a variety of cellular stresses (14). A number of stresses, including damage to chromosomal DNA incurred by ionizing irradiation and exposure to ultraviolet light may activate a p53-mediated growth-suppressive response. Approximately half of all human cancers harbor mutations in p53, which leads to loss of tumor suppressor function and/or 
gain of new oncogenic activity (15). Loss of p53 function can contribute not only to aggressive tumor behavior, but also to therapeutic resistance (14).

Small-molecule RITA (reactivation of p53 and induction of tumor cell apoptosis) has been shown to bind p53 directly, inducing a conformational change that prevents its interaction with several inhibitory proteins including MDM2, Parc and iASPP (16). RITA reportedly induces p53-dependent apoptosis in tumor cells expressing wild-type p53 (wtp53), as well as in tumor cells expressing mutant or null p53 (15). A recent study demonstrated that RITA increases radiosensitivity in head and neck squamous cell carcinoma cells expressing mutant p53 (mtp53) (17).

Commonly used human cervical cancer cell lines, C-33A and HT-3, contain p53 codon mutations and are human papillomavirus (HPV)-negative. In contrast, five HPV-positive cervical cancer cell lines (HeLa S-3, Caski, SiHa, C-4I and ME-180) contain wild-type p53 $(18,19)$. It has been reported that RITA may protect p53 from HPV-E6-mediated degradation in HPV-positive, wtp53-expressing cervical cancer cells (20). However, the effect of RITA on mutant p53 (mtp53)-expressing cervical cancer cells has not been studied.

In the present study, we explored for the first time the effects and the underlying mechanisms of RITA in regards to radiosensitivity and ER stress in mtp53-expressing cervical cancer cells.

\section{Materials and methods}

Cell culture and radiosensitivity assay. Human cervix cancer cell lines C-33A (HTB-31) and HT-3 (HTB-32) were purchased from the American Type Culture Collection (ATCC; Manassas, VA, USA) and cultured in Dulbecco's modified Eagle medium (DMEM; Life Technologies, Carlsbad, CA, USA) containing $10 \%$ heat-inactivated FBS (Life Technologies) and $100 \mathrm{U} / \mathrm{ml}$ penicillin-streptomycin (Sigma-Aldrich, Beijing, China) in an incubator with a humidified atmosphere of $95 \%$ air and 5\% $\mathrm{CO}_{2}$ at $37^{\circ} \mathrm{C}$. Cells were plated at $4 \times 10^{3}$ cells/well into $96-$ well plates and cultured for $3 \mathrm{~h}$ for the cells to adhere to the plates. Then, the cells were cultured with or without $1 \mu \mathrm{M}$ of RITA for $24 \mathrm{~h}$ before irradiation, which was performed at a dose rate of $200 \mathrm{cGy} / \mathrm{min}$ for the time required to generate dose curves of 2, 4, 6 and 8 Gy with linear accelerator Clinac 2100C (Varian Medical Systems, Palo Alto, CA, USA) operating at $6 \mathrm{MV}$. Corresponding controls were sham-irradiated. Colony-forming assays were performed immediately after irradiation by plating the cells into 6-well culture dishes. After 17 days, the colonies were fixed with $6.0 \%$ glutaraldehyde, stained with $0.5 \%$ crystal violet and counted. Survival curves were fitted with GraphPad Prism version 5.0 (GraphPad Software, La Jolla, CA, USA). Each experiment was repeated three times in duplicates.

Stable lentiviral transduction. The p53 (sc-29435-V) and the IRE1 $\alpha$ (sc-40705-V) shRNA lentiviral particles purchased from Santa Cruz Biotechnology (Santa Cruz, CA, USA) contain expression constructs encoding target-specific shRNA designed to specifically knock down human p53 and IRE1 $\alpha$ gene expression, respectively. The control shRNA lentiviral particles (sc-108080; Santa Cruz Biotechnology) contain a scrambled shRNA sequence that will not lead to specific degradation of any cellular mRNA. Lentiviral transduction was performed, and pools of stable transductants were generated via selection with puromycin $(6 \mu \mathrm{g} / \mathrm{ml}$; Sigma-Aldrich) according to the manufacturer's instructions (Santa Cruz Biotechnology).

Western blot analysis. C-33A and HT-3 cells was lysed with a hypotonic buffer containing $2 \%$ Nonidet-P and a protease inhibitor cocktail (Sigma-Aldrich) by sonication three times for $3 \mathrm{sec}$ on ice. The supernatant obtained after centrifugation at $2,000 \mathrm{x} \mathrm{g}$ for $15 \mathrm{~min}$ at $4^{\circ} \mathrm{C}$ was used for protein concentration determination by the Coomassie blue method. Equal amounts of proteins for each sample were separated on $10 \%$ SDS-polyacrylamide gel and blotted onto a polyvinylidene difluoride microporous membrane (Millipore, Billerica, MA, USA). Membranes were incubated for $1 \mathrm{~h}$ with a 1:1,000 dilution of rabbit anti-human polyclonal p53 (FL-393; sc-6243) antibody (Santa Cruz Biotechnology), rabbit anti-human polyclonal IRE1 $\alpha$ (H-190; sc-20790) antibody (Santa Cruz Biotechnology) or mouse anti-human monoclonal glyceraldehyde-3-phosphate dehydrogenase (GAPDH) (6C5; sc-32233) antibody (Santa Cruz Biotechnology) and then washed and revealed using bovine anti-rabbit (sc-2370) or anti-mouse (sc-2371) secondary antibody $(1: 5,000,1 \mathrm{~h})$. Peroxidase was revealed with a GE Healthcare ECL kit (Shanghai, China). Three independent experiments were performed.

Real-time quantitative reverse transcription PCR. RNA was prepared from the cells using TRIzol reagent. The cDNAs were synthesized using SuperScript II reverse transcriptase (Life Technologies). Real-time quantitative PCR was performed on an Abi-Prism 7700 Sequence Detection System, using the fluorescent dye SYBR-Green Master Mix (Applied Biosystems, Beijing, China) as described by the manufacturer. The primers used were as follows: for IRE1 $\alpha, 5^{\prime}$-GCCACC CTGCAAGAGTATGT-3' (forward) and 5'-ATGTTGAGG GAGTGGAGGTG-3' (reverse); for spliced XBP1 mRNA (XBP1spl), 5'-TGCTGAGTCCGCAGCAGGTG-3' (forward) and 5'-GCTGGCAGGCTCTGGGGAAG-3' (reverse); for GAPDH, 5'-GACTCATGACCACAGTCCATG C-3' (forward) and 5'-AGAGGCAGGGATGATGTTCTG-3' (reverse). Relative quantification of the level of IRE1 $\alpha$ mRNA or spliced XBP1 mRNA was determined using the $2^{-\Delta \Delta \mathrm{Ct}}$ method and normalized against that of GAPDH in the same sample (19). Each experiment was repeated three times in duplicates.

Luciferase assay. Cells were transfected with a commercially available human IRE1 $\alpha$ promoter/luciferase reporter (S720185; SwitchGear Genomics, Shanghai, China) using Lipofectamine 2000 transfection reagent (Life Technologies) and then cultured for $24 \mathrm{~h}$. Luciferase assays were performed with the LightSwitch luciferase assay kit (LS010; SwitchGear Genomics) according to the manufacturer's instructions. Each experiment was repeated three times in duplicates.

Transcriptional pulse-chase assay. A Click-iT Nascent RNA Capture kit (C-10365; Life Technologies) was used to determine the stability of IRE1 $\alpha$ mRNA according to the manufacturer's instructions. Briefly, C-33A and HT-3 cells were labeled with 

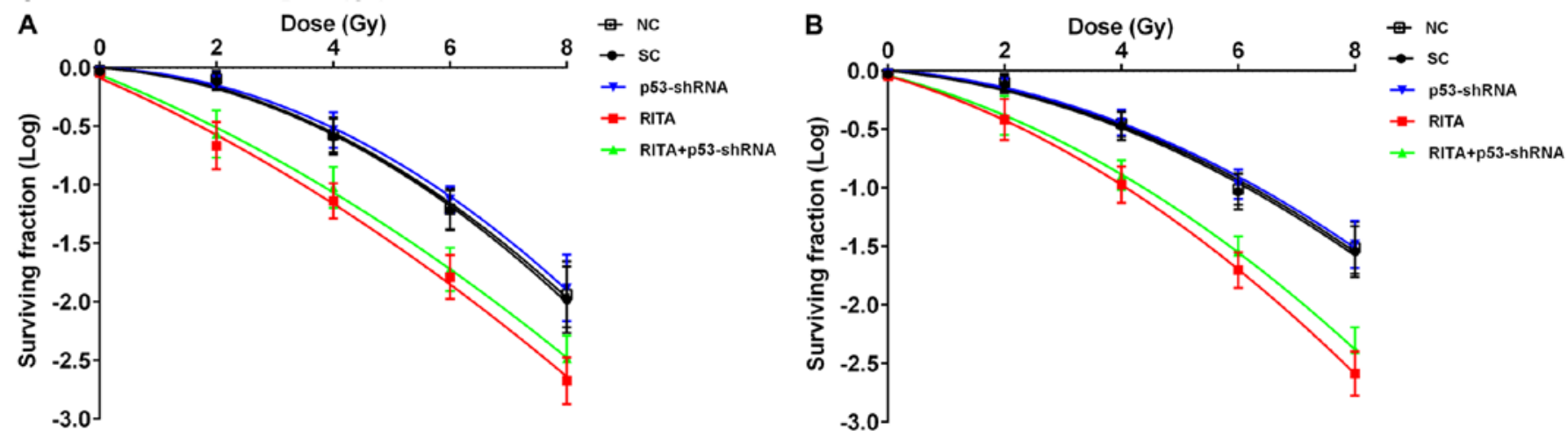

Figure 1. Effects of RITA on the survival of cervical cancer cells under irradiation. Human (A) C-33A and (B) HT-3 cervical cancer cells with or without stable transduction of lentiviral p53-shRNA were cultured with or without $1 \mu \mathrm{M}$ of RITA for $24 \mathrm{~h}$ before irradiation at $2,4,6$ and 8 Gy with a linear accelerator operating at $200 \mathrm{cGy} / \mathrm{min}$ and $6 \mathrm{MV}$. Colony-forming assays were performed immediately after irradiation. After 17 days, colonies were fixed, stained and counted. Dose-survival fraction curves were fitted with GraphPad Prism version 5.0. The experimental groups were as follows: NC, normal control cells; SC, cells stably transduced with scramble control shRNA; p53-shRNA, cells stably transduced with lentiviral p53-shRNA; RITA, cells treated with $1 \mu$ M of RITA for $24 \mathrm{~h}$ before irradiation; RITA+p53-shRNA, cells stably transduced with lentiviral p53-shRNA and treated with $1 \mu \mathrm{M}$ of RITA for $24 \mathrm{~h}$ before irradiation.

$0.2 \mathrm{mM}$ ethynyl uridine (EU) and incubated at $37^{\circ} \mathrm{C}$ for $4 \mathrm{~h}$. The cells were then allowed to recover in EU-free medium for $0,1,2$ or $4 \mathrm{~h}$, respectively. Total RNA was extracted and $5 \mu \mathrm{g}$ of total RNA was mixed with Click-iT reaction cocktail. Immediately, the reaction buffer additive 1 was added, followed by reaction buffer additive 2 exactly 3 min after addition of the first additive and the reaction was carried out for $30 \mathrm{~min}$ at room temperature. Following incubation, the 'clicked' RNA was re-purified by ammonium acetate precipitation and captured by streptavidin magnetic beads. The captured RNA was in-bead converted to cDNA using SuperScript III reverse transcriptase (Life Technologies). Then, the level of the IRE1 $\alpha$ mRNA or the spliced XBP1 mRNA was determined with realtime quantitative reverse transcription PCR as described above.

Cell apoptosis assay. Cells were plated at $4 \times 10^{3}$ cells/well into 96-well plates and cultured for $3 \mathrm{~h}$ for the cells to adhere to the plates. Then, the cells were cultured with or without $1 \mu \mathrm{M}$ of RITA for $24 \mathrm{~h}$ before sham-irradiation or irradiation at a dose of 6 Gy with linear accelerator Clinac 2100C operating at $6 \mathrm{MV}$. Cell apoptosis was measured $24 \mathrm{~h}$ after irradiation with a microplate reader-based TiterTACS in situ apoptosis detection kit (4822-96-K; R\&D systems, Minneapolis, MN, USA) according to the manufacturer's instructions (21). Each experiment was repeated three times in duplicates.

Statistical analysis. Statistical analyses were performed with SPSS for Windows 10.0 (SPSS Inc., Chicago, IL, USA). All data values are expressed as means $\pm \mathrm{SD}$. Comparison of means between two groups was performed with Student's t-tests. Comparisons of means among multiple groups were performed with one-way ANOVA followed by post hoc pairwise comparisons using Tukey's tests. A two-tailed $\mathrm{P}<0.05$ was considered statistically significant in the present study.

\section{Results}

Effects of RITA on survival and apoptosis of mtp53-expressing cervical cancer cells under irradiation. To explore the effects of RITA on the radiosensitivity of mtp53-expressing cervical cancer cells, we treated human C-33A and HT-3 cervical cancer cells with $1 \mu \mathrm{M}$ of RITA for $24 \mathrm{~h}$ before irradiation at 2, 4, 6 and 8 Gy. As shown in Fig. 1, RITA markedly decreased cell survival under irradiation compared with the controls, indicating that RITA may increase the radiosensitivity of C-33A and HT-3 cells. To determine the potential role of p53 in the radiosensitivity-enhancing effect of RITA, we knocked down p53 in both cell lines, even though the cells only express mtp53. As shown in Fig. 2, stable transduction of lentiviral p53-shRNA knocked down the endogenous p53 expression by over $85 \%$ in both the C-33A and HT-3 cells. Obviously, knockdown of p53 did not show any significant effect on RITA-induced radiosensitivity in the cells (Fig. 1).

To explore the effects of RITA on irradiation-induced apoptosis in mtp53-expressing cervical cancer cells, we next measured apoptosis in the C-33A and HT-3 cells with or without RITA treatment under sham 0 or 6 Gy of irradiation. As shown in Fig. 3, compared with the controls, RITA treatment at $1 \mu \mathrm{M}$ for $24 \mathrm{~h}$ showed no significant effect on apoptosis in the C-33A and HT-3 cells under sham irradiation. The RITA $\mathrm{IC}_{50}$ value for C-33A and HT-3 cells under sham irradiation was calculated to be 15.6 and $18.3 \mu \mathrm{M}$, respectively. However, in the cells under irradiation, RITA treatment at $1 \mu \mathrm{M}$ for $24 \mathrm{~h}$ increased the apoptosis rate by $\sim 2$-fold in both cell lines compared with the controls (Fig. 3). Knockdown of p53 did not significantly alter the apoptotic effect of RITA on the cells under irradiation (Fig. 3).

Collectively, the findings suggested that RITA induced radiosensitivity and irradiation-induced apoptosis in mtp53-expressing cervical cancer cells by a p53-independent mechanism.

Effects of RITA/IREI $\alpha$ signaling on survival and apoptosis of mtp53-expressing cervical cancer cells under irradiation. As shown in Fig. 4, compared with the controls, RITA showed no significant effect on the protein level of IRE1 $\alpha$ in the C-33A and HT-3 cells under sham irradiation. However, in cells under irradiation, RITA increased the protein level of IRE1 $\alpha$ by 

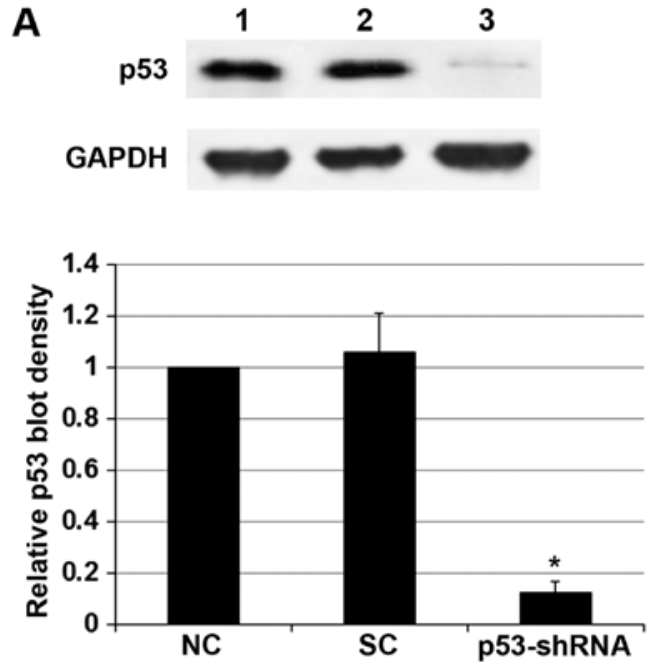

B
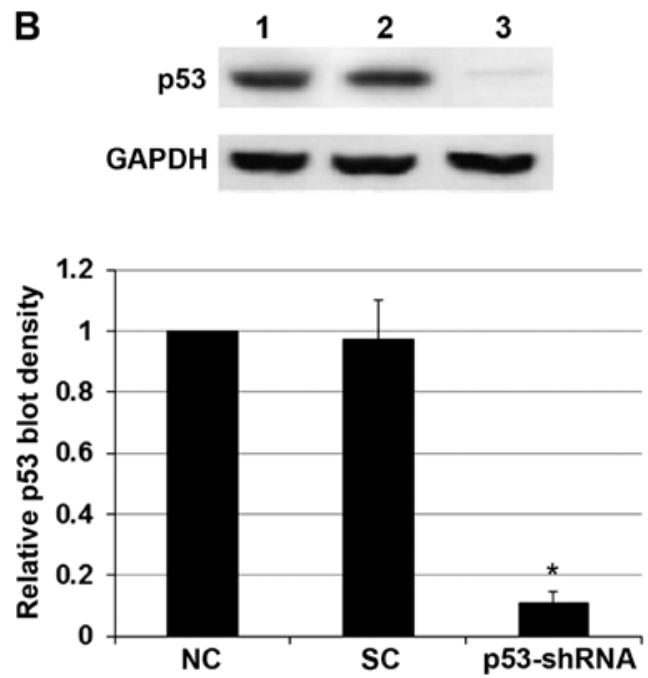

Figure 2. Knockdown of p53 in cervical cancer cells. (A) C-33A and (B) HT-3 cells were stably transduced with lentiviral p53-shRNA to knock down the expression of $\mathrm{p} 53$. The protein levels of p53 were determined by western blot analyses in normal control cells (NC, lane 1), cells stably transduced with scramble control shRNA (SC, lane 2) and cells stably transduced with lentiviral p53-shRNA (lane 3). GAPDH blotting was used as a loading control. Density of the western blot analysis was determined by densitometry, and the density of the p53 blot was normalized against that of the GAPDH blot in the same sample to obtain a relative blot density, which was expressed as a fold-change to that of $\mathrm{NC}$ (designated as 1 ). ${ }^{*} \mathrm{P}<0.05$ vs. controls ( $\mathrm{NC}$ and $\mathrm{SC}$ ). NC, normal control cells; SC, cells stably transduced with scramble control shRNA; GAPDH, glyceraldehyde-3-phosphate dehydrogenase; p53-shRNA, cells stably transduced with lentiviral p53-shRNA.
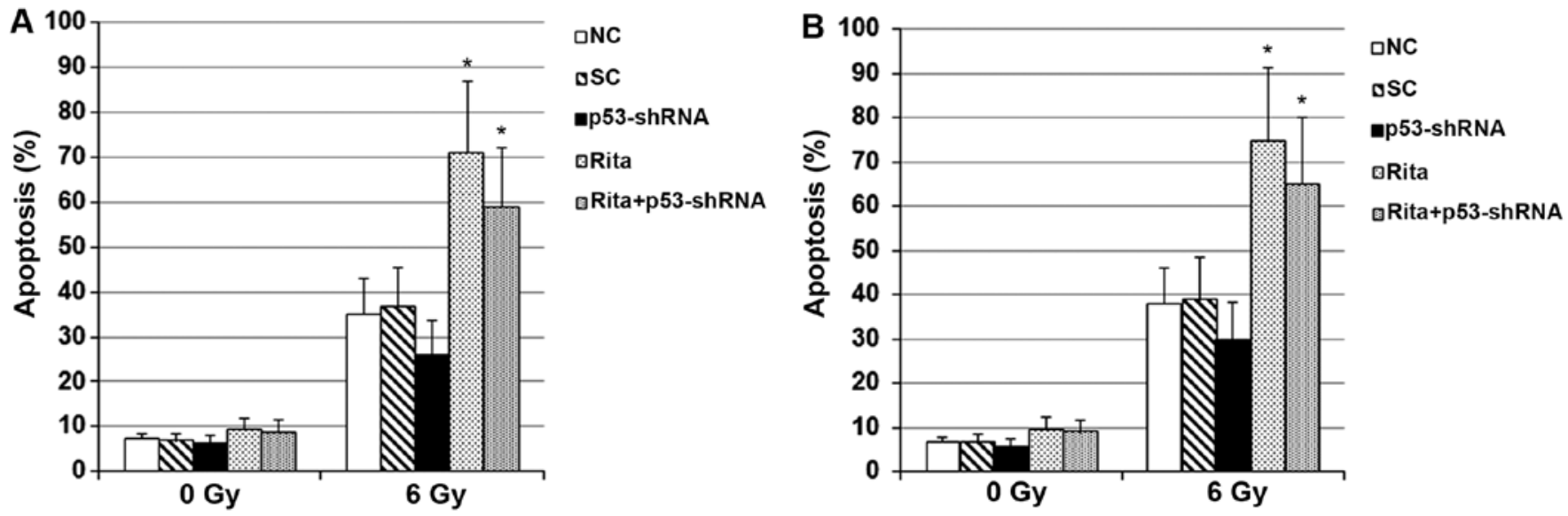

Figure 3. Effects of RITA on the apoptosis in cervical cancer cells in the presence or absence of irradiation. (A) C-33A and (B) HT-3 cells with or without stable transduction of lentiviral p53-shRNA were cultured with or without $1 \mu \mathrm{M}$ of RITA for $24 \mathrm{~h}$ before irradiation at 0 (sham irradiation) or 6 Gy with linear accelerator Clinac $2100 \mathrm{C}$ operating at $200 \mathrm{cGy} / \mathrm{min}$ and $6 \mathrm{MV}$. The apoptosis rate was measured $24 \mathrm{~h}$ after irradiation with a microplate reader-based TiterTACS in situ apoptosis detection kit and shown as percentages. The experimental groups were as follows: NC, normal control cells; SC, cells stably transduced with scramble control shRNA; p53-shRNA, cells stably transduced with lentiviral p53-shRNA; RITA, cells treated with $1 \mu \mathrm{M}$ of RITA for $24 \mathrm{~h}$ before irradiation; RITA+p53-shRNA, cells stably transduced with lentiviral p53-shRNA and treated with $1 \mu \mathrm{M}$ of RITA for $24 \mathrm{~h}$ before irradiation. "P $<0.05$ vs. controls (NC and SC).

2.5-fold in the C-33A cells and by $\sim 3.6$-fold in the HT-3 cells, respectively (Fig. 4). Notably, compared with the controls under sham irradiation, the irradiation treatment increased the protein level of IRE1 $\alpha$ by $\sim 3$-fold in the C-33A and by $\sim 2$-fold in the HT-3 cells, respectively (Fig. 4). Knockdown of p53 did not significantly alter the effect of RITA on the expression of IRE1 $\alpha$ in the presence or absence of irradiation (Fig. 4).

To determine the potential role of IRE1 $\alpha$ in the radiosensitivity-enhancing effect of RITA on mtp53-expressing cervical cancer cells, we knocked down IRE1 $\alpha$ in the C-33A and HT-3 cells. As shown in Fig. 5, even under irradiation, stable transduction of lentiviral IRE1 $\alpha$-shRNA knocked down the endogenous IRE1 $\alpha$ expression by $\sim 80 \%$ in both the C-33A and HT-3 cells; the addition of RITA treatment $(1 \mu \mathrm{M}$ for $24 \mathrm{~h}$ ) only partially restored the expression of IRE1 $\alpha$ by $28 \%$ in the C-33A cells and by $37 \%$ in the HT- 3 cells, respectively (Fig. 5). As shown in Fig. 6, RITA markedly decreased cell survival under irradiation compared with the controls, which was largely reversed by the knockdown of IRE1 $\alpha$. Notably, knockdown of IRE1 $\alpha$ itself did not significantly improve cell survival compared with the controls (Fig. 6). Similarly, in the cell apoptosis assays, whereas knockdown of IRE1 $\alpha$ reversed the apoptotic effect of RITA in the C-33A and HT-3 cells under irradiation, it did not significantly decrease 

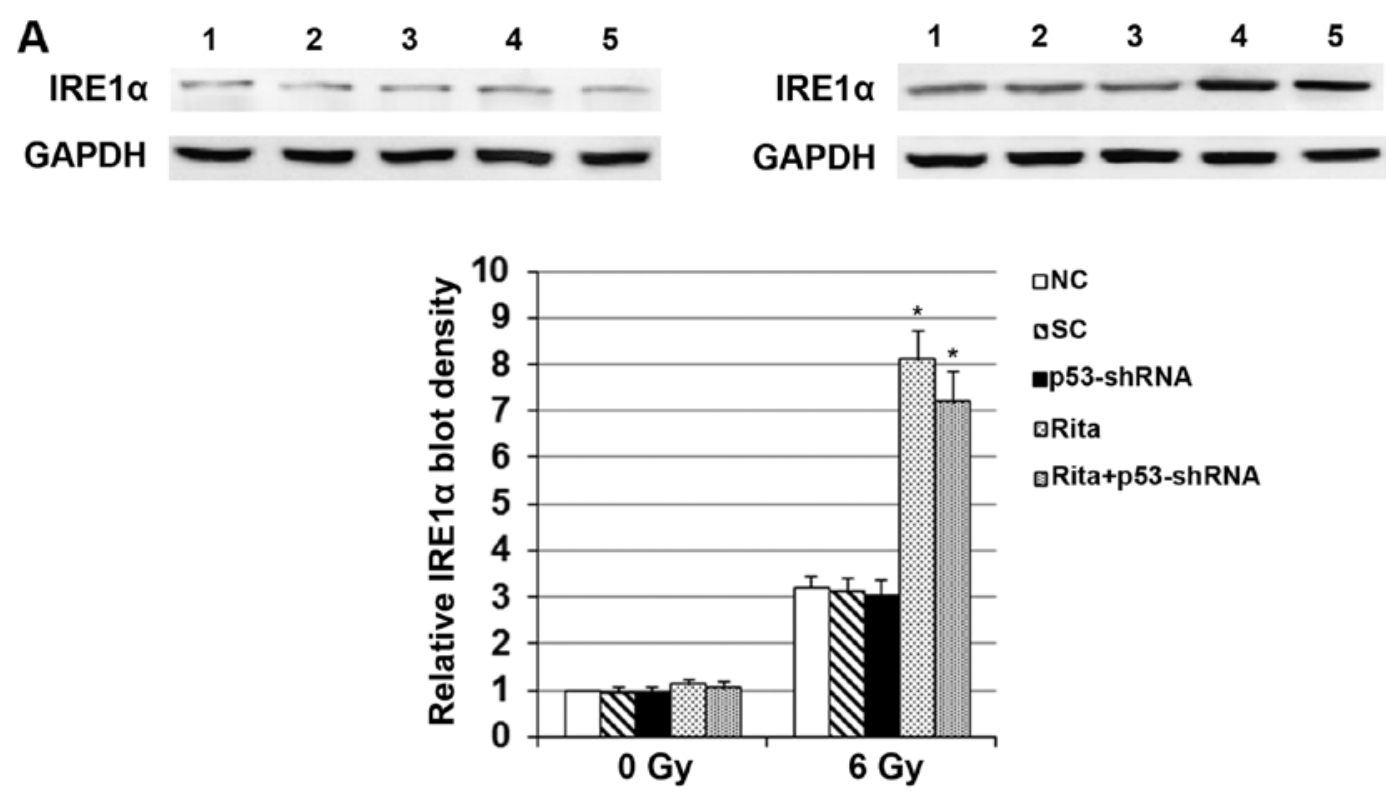

口NC

oSC

up53-shRNA

QRita

oRita+p53-shRNA
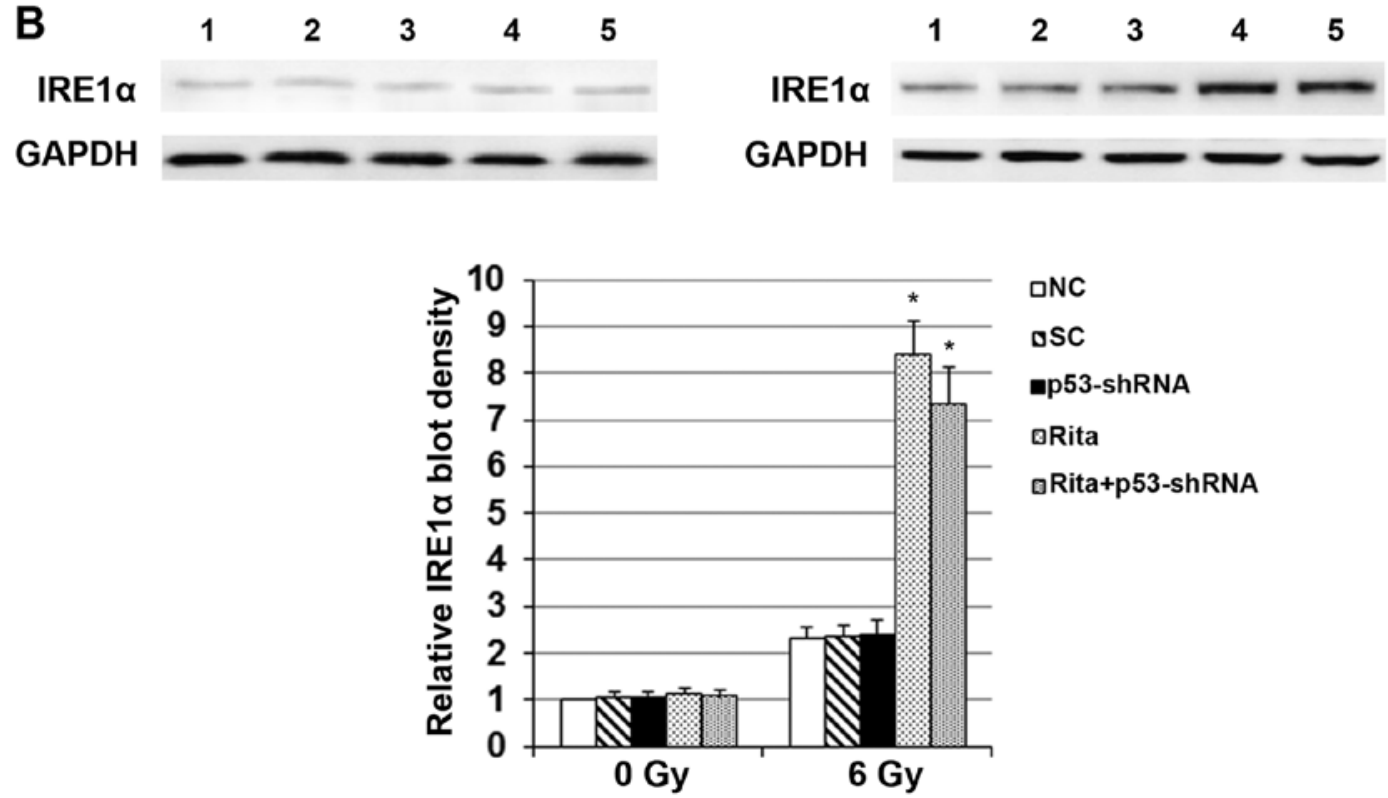

口NC

oSC

mp53-shRNA

oRita

aRita+p53-shRNA

Figure 4. Effects of RITA on the protein levels of IRE1 $\alpha$ in cervical cancer cells in the presence or absence of irradiation. (A) C-33A and (B) HT-3 cells with or without stable transduction of lentiviral p53-shRNA were cultured with or without $1 \mu \mathrm{M}$ of RITA for $24 \mathrm{~h}$ before irradiation at 0 (sham irradiation) (left panel) or $6 \mathrm{~Gy}$ (right panel) with a linear accelerator operating at $200 \mathrm{cGy} / \mathrm{min}$ and $6 \mathrm{MV}$. The protein levels of IRE1 $\alpha$ were determined by western blot analyses $24 \mathrm{~h}$ after irradiation in normal control cells (NC, lane 1), cells stably transduced with scramble control shRNA (SC, lane 2), cells stably transduced with lentiviral p53-shRNA (lane 3), cells treated with $1 \mu \mathrm{M}$ of RITA for $24 \mathrm{~h}$ before irradiation (lane 4) and cells stably transduced with lentiviral p53-shRNA and treated with $1 \mu \mathrm{M}$ of RITA for $24 \mathrm{~h}$ before irradiation (RITA+p53-shRNA, lane 5). GAPDH blotting was used as a loading control. Density of the western blot analysis was measured by densitometry, and the density of the IREl $\alpha$ blot was normalized against that of the GAPDH blot in the same sample to obtain a relative blot density, which was expressed as a fold-change to that of NC at $0 \mathrm{~Gy}$ (designated as 1). "P<0.05 vs. controls (NC and SC). NC, normal control cells; SC, cells stably transduced with scramble control shRNA; p53-shRNA, cells stably transduced with lentiviral p53-shRNA; RITA, cells treated with $1 \mu$ M of RITA for $24 \mathrm{~h}$ before irradiation; RITA+p53-shRNA, cells stably transduced with lentiviral p53-shRNA and treated with $1 \mu \mathrm{M}$ of RITA for $24 \mathrm{~h}$ before irradiation; GAPDH, glyceraldehyde-3-phosphate dehydrogenase.

cell apoptosis compared with the controls. Collectively, the findings suggested that RITA enhanced radiosensitivity and irradiation-induced apoptosis in the mtp53-expressing cervical cancer cells largely through inducing the expression of IRE1 $\alpha$.

In the IRE1 branch of ER stress-triggered UPR, activation of IRE1 leads to cleavage of a 26-nucleotide intron from the XBP1 mRNA. The spliced XBP1 mRNA is considered to be an important marker for ER stress, particularly for IRE1-mediated UPR $(8,9)$. We next examined whether RITA enhanced ER stress in the C-33A and HT-3 cells under irradiation, using XBP1 as a marker. As shown in Fig. 8, compared with the controls, RITA showed no significant effect on the spliced mRNA level of XBP1 in the C-33A and HT-3 cells under sham irradiation. However, in cells under irradiation, RITA increased the spliced mRNA level of XBP1 by $\sim 1.8$-fold in the C-33A cells and by $\sim 3$-fold in the HT-3 cells, respectively, which was completely abolished by the knockdown of IRE1 $\alpha$ (Fig. 8). The findings suggested that RITA enhances 

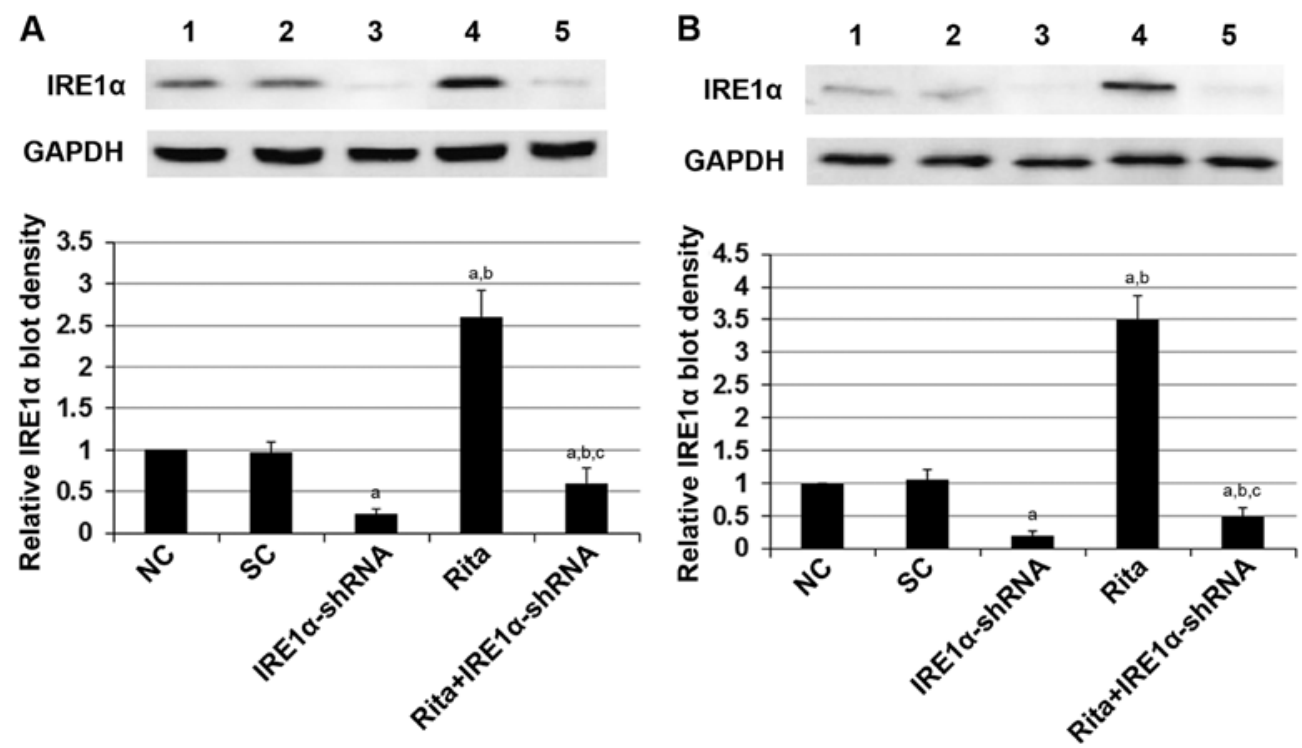

Figure 5. Knockdown of IRE1 $\alpha$ in cervical cancer cells. (A) C-33A and (B) HT-3 cells stably transduced with lentiviral IRE1 $\alpha$-shRNA were cultured with or without $1 \mu \mathrm{M}$ of RITA for $24 \mathrm{~h}$ before irradiation at $6 \mathrm{~Gy}$ with a linear accelerator operating at $200 \mathrm{cGy} / \mathrm{min}$ and $6 \mathrm{MV}$. Twenty-four hours after irradiation, the protein levels of IRE1 $\alpha$ were determined by western blot analyses $24 \mathrm{~h}$ after irradiation in normal control cells (NC, lane 1), cells stably transduced with scramble control shRNA (SC, lane 2), cells stably transduced with lentiviral IRE1 $\alpha$-shRNA (lane 3), cells treated with $1 \mu \mathrm{M}$ of RITA for $24 \mathrm{~h}$ before irradiation (lane 4) and cells stably transduced with lentiviral IRE1 $\alpha$-shRNA and treated with $1 \mu \mathrm{M}$ of RITA for $24 \mathrm{~h}$ before irradiation (RITA+IRE1 $\alpha$-shRNA, lane 5) GAPDH blotting was used as a loading control. Density of the western blot analysis was measured by densitometry and the density of the IRE1 $\alpha$ blot was normalized against that of the GAPDH blot in the same sample to obtain a relative blot density, which was expressed as a fold-change to that of NC (designated as 1). ${ }^{a} \mathrm{P}<0.05$ vs. controls (NC and SC); ${ }^{b} \mathrm{P}<0.05$ vs. IRE1 $\alpha$-shRNA; ${ }^{\mathrm{P}}<0.05$ vs. RITA. NC, normal control cells; SC, cells stably transduced with scramble control shRNA; RITA, cells treated with $1 \mu \mathrm{M}$ of RITA for $24 \mathrm{~h}$ before irradiation; RITA+p53-shRNA, cells stably transduced with lentiviral p53-shRNA and treated with $1 \mu \mathrm{M}$ of RITA for $24 \mathrm{~h}$ before irradiation; GAPDH, glyceraldehyde-3-phosphate dehydrogenase.
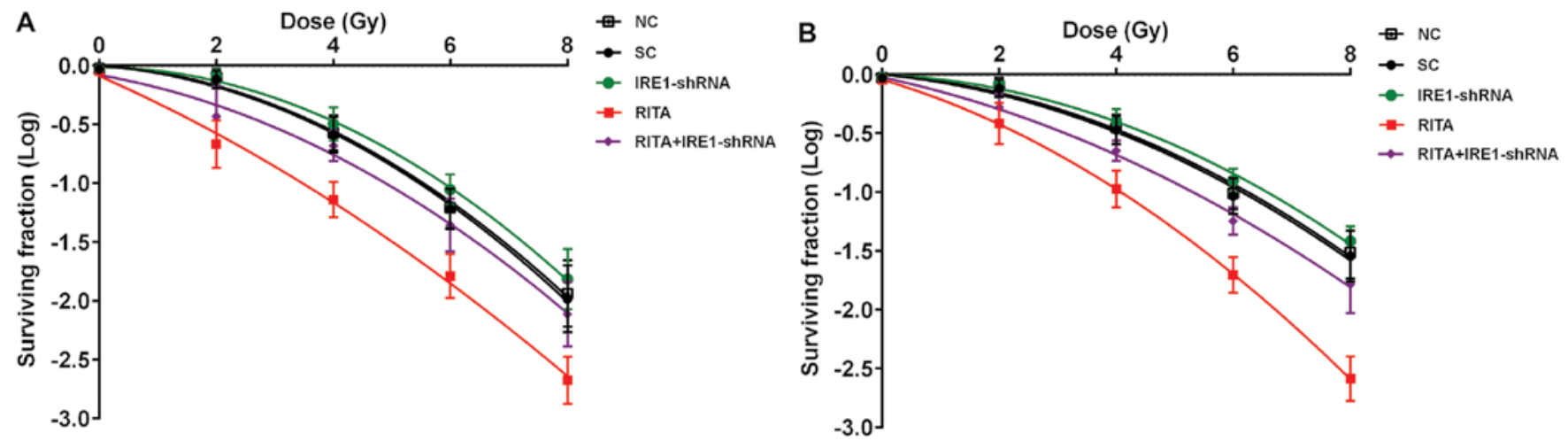

Figure 6. Effects of RITA and IRE1 $\alpha$ on the survival of cervical cancer cells under irradiation. (A) C-33A and (B) HT-3 cervical cancer cells with or without stable transduction of lentiviral IRE1 $\alpha$-shRNA were cultured with or without $1 \mu \mathrm{M}$ of RITA for $24 \mathrm{~h}$ before irradiation at $2,4,6$ and 8 Gy with a linear accelerator operating at $200 \mathrm{cGy} / \mathrm{min}$ and $6 \mathrm{MV}$. Colony-forming assays were performed immediately after irradiation. After 17 days, colonies were fixed, stained and counted. Dose-survival fraction curves were fitted with GraphPad Prism version 5.0. The experimental groups were as follows: NC, normal control cells; SC, cells stably transduced with scramble control shRNA; IRE1 $\alpha$-shRNA, cells stably transduced with lentiviral IRE1 $\alpha$-shRNA; RITA, cells treated with $1 \mu \mathrm{M}$ of RITA for $24 \mathrm{~h}$ before irradiation.

irradiation-induced ER stress through the IRE1 $\alpha / \mathrm{XBP} 1$ branch and promotes apoptosis in mtp53-expressing cervical cancer cells.

Effects of RITA on the stability of IREI $\alpha$ mRNA in mtp53-expressing cervical cancer cells under irradiation. As shown in Fig. 9A, compared with the controls, RITA markedly elevated the mRNA level of IRE1 $\alpha$ in the C-33A and HT-3 cells under irradiation, indicating that RITA induced the expression of IRE1 $\alpha$ at the mRNA level in mtp53-expressing cervical cancer cells under irradiation. To test whether RITA exerted this effect through transactivation of the IRE1 $\alpha$ gene promoter, we transfected the C-33A and HT-3 cells with a human IRE1 $\alpha$ gene promoter/luciferase reporter. As shown in Fig. 9B, luciferase reporter assays revealed that RITA had no significant effect on the IRE1 $\alpha$ promoter activity in the presence or absence of irradiation treatment, suggesting that RITA did not upregulate the IRE1 $\alpha$ mRNA level in the irradiated C-33A and HT-3 cells at the gene promoter/transcription level. We next examined the effect of RITA on the stability of 

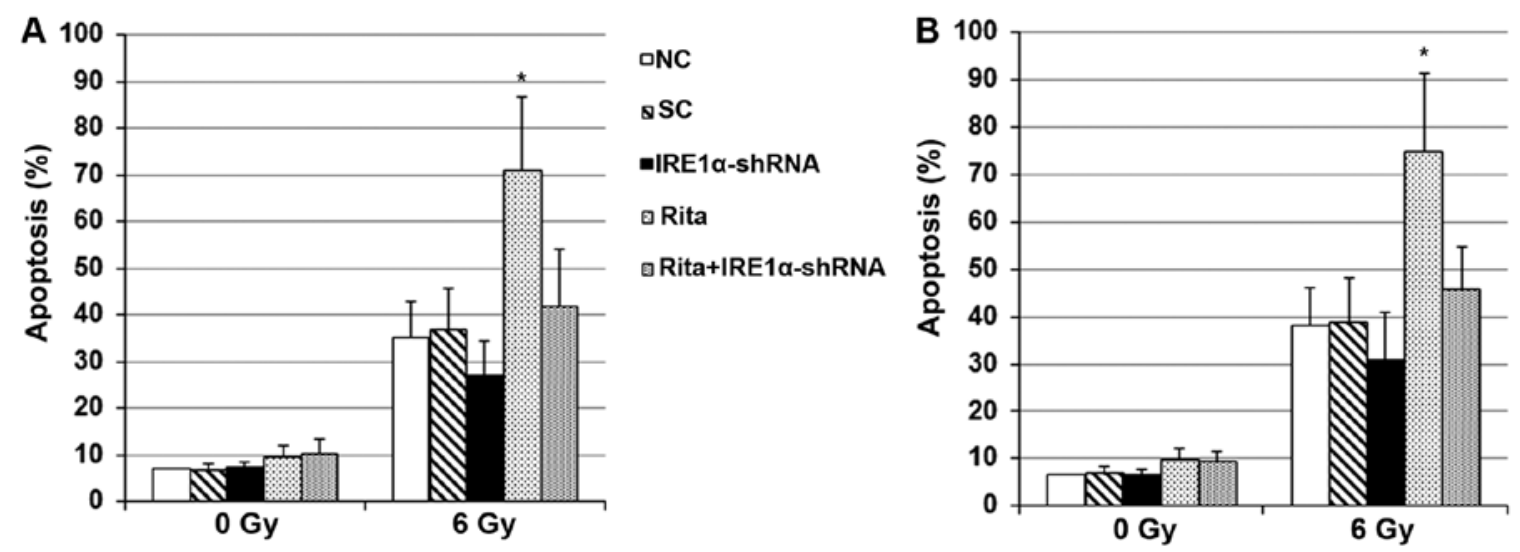

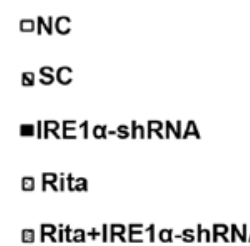

Figure 7. Effects of RITA and IRE1 $\alpha$ on apoptosis in cervical cancer cells in the presence or absence of irradiation. (A) C-33A and (B) HT-3 cells with or without stable transduction of lentiviral IREl $\alpha$-shRNA were cultured with or without $1 \mu \mathrm{M}$ of RITA for $24 \mathrm{~h}$ before irradiation at 0 (sham irradiation) or $6 \mathrm{~Gy}$ with a linear accelerator operating at $200 \mathrm{cGy} / \mathrm{min}$ and $6 \mathrm{MV}$. The apoptosis rate was measured $24 \mathrm{~h}$ after irradiation with a microplate reader-based TiterTACS in situ apoptosis detection kit and shown as percentages. The experimental groups were as follows: NC, normal control cells; SC, cells stably trasduced with scramble control sh RNA; IRE1 $\alpha$-shRNA, cells stably transduced with lentiviral IRE1 $\alpha$-shRNA; RITA, cells treated with $1 \mu$ M of RITA for $24 \mathrm{~h}$ before irradiation; RITA+IRE1 $\alpha$-shRNA, RITA, cells stably transduced with lentiviral IRE1 $\alpha$-shRNA and treated with $1 \mu \mathrm{M}$ of RITA for $24 \mathrm{~h}$ before irradiation. ${ }^{\mathrm{a} P}<0.05$ vs. controls (NC and $\mathrm{SC}$ ), ${ }^{\mathrm{b}} \mathrm{P}<0.05$ vs. IRE $1 \alpha$-shRNA and ${ }^{\mathrm{c}} \mathrm{P}<0.05$ vs. RITA.
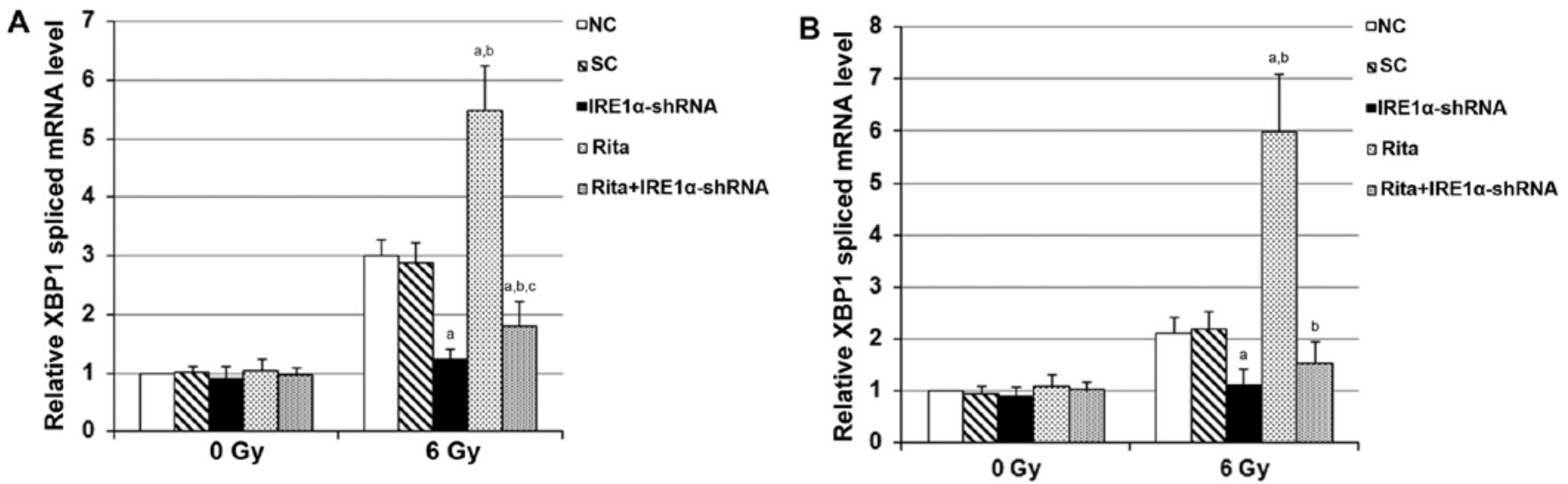

Figure 8. Effects of RITA and IRE1 $\alpha$ on spliced mRNA level of XBP1 in cervical cancer cells in the presence or absence of irradiation. (A) C-33A and (B) HT-3 cells with or without stable transduction of lentiviral IREl $\alpha$-shRNA were cultured with or without $1 \mu \mathrm{M}$ of RITA for $24 \mathrm{~h}$ before irradiation at 0 (sham irradiation) or $6 \mathrm{~Gy}$ with a linear accelerator operating at $200 \mathrm{cGy} / \mathrm{min}$ and $6 \mathrm{MV}$. The spliced mRNA level of XBP1 was determined $24 \mathrm{~h}$ after irradiation with real-time reverse transcription PCR assays in NC, cells stably transduced with SC, cells stably transduced with lentiviral IRE1 $\alpha$-shRNA, cells treated with $1 \mu \mathrm{M}$ of RITA for $24 \mathrm{~h}$ before irradiation and cells stably transduced with lentiviral IRE1 $\alpha$-shRNA and treated with $1 \mu \mathrm{M}$ of RITA for $24 \mathrm{~h}$ before irradiation (RITA+IRE1 $\alpha$-shRNA). The spliced mRNA level of XBP1 was expressed as fold changes to that of NC at 0 Gy (designated as 1). NC, normal control cells; SC, cells stably trasduced with scramble control sh RNA; IRE1 $\alpha$-shRNA, cells stably transduced with lentiviral IRE1 $\alpha$-shRNA; RITA, cells treated with $1 \mu$ M of RITA for $24 \mathrm{~h}$ before irradiation; RITA+IRE1 $\alpha$-shRNA, RITA, cells stably transduced with lentiviral IRE1 $\alpha$-shRNA and treated with $1 \mu \mathrm{M}$ of RITA for $24 \mathrm{~h}$ before irradiation. ${ }^{a} \mathrm{P}<0.05$ vs. controls (NC and $\mathrm{SC}$ ); ${ }^{\mathrm{P}} \mathrm{P}<0.05$ vs. IRE $1 \alpha$-shRNA; ${ }^{\mathrm{P}} \mathrm{P}<0.05$ vs. $\mathrm{RITA}$.

IREl $\alpha$ mRNA with transcriptional pulse-chase assays, using a Click-iT Nascent RNA Capture kit (Life Technologies). Briefly, immediately after irradiation treatment, the C-33A and HT- 3 cells were labeled with EU and incubated at $37^{\circ} \mathrm{C}$ for $4 \mathrm{~h}$. Cells were then allowed to recover in EU-free medium for 0, 1,2 or $4 \mathrm{~h}$, respectively. Then, the labeled RNA was captured and subjected to real-time reverse transcription PCR assays to determine the IRE1 $\alpha$ mRNA. As shown in Fig. 10, at $1 \mathrm{~h}$, the IRE1 $\alpha$ mRNA level in the control cells dropped to $62-65 \%$ of that at $0 \mathrm{~h}$; at $4 \mathrm{~h}$, the IRE1 $\alpha$ mRNA level in the control cells dropped to $\sim 10 \%$ of that at $0 \mathrm{~h}$. In cells treated with RITA, however, the IRE1 $\alpha$ mRNA level at $1 \mathrm{~h}$ remained above $85 \%$ of that at $0 \mathrm{~h}$; at $4 \mathrm{~h}$, the IRE1 $\alpha$ mRNA level remained above $40 \%$ of that at $0 \mathrm{~h}$. The findings suggested that in mtp53-expressing cervical cancer cells under irradiation, RITA induced the expression of IRE1 $\alpha$ mainly by increasing its mRNA stability.

\section{Discussion}

In the present study, we demonstrated that RITA enhanced irradiation-induced apoptosis in mtp53-expressing cervical cancer cells mainly by upregulating the expression of IRE1 $\alpha$ and IRE1 $\alpha /$ XBP1 signaling.

RITA has been shown to reactivate wtp53 function as well as to rescue the function of p53 mutants in different types of human tumor cells and induce p53-dependent apoptosis (22). It reportedly may protect $\mathrm{p} 53$ from HPV-E6-mediated degradation in HPV-positive wtp53-expressing cervical cancer 

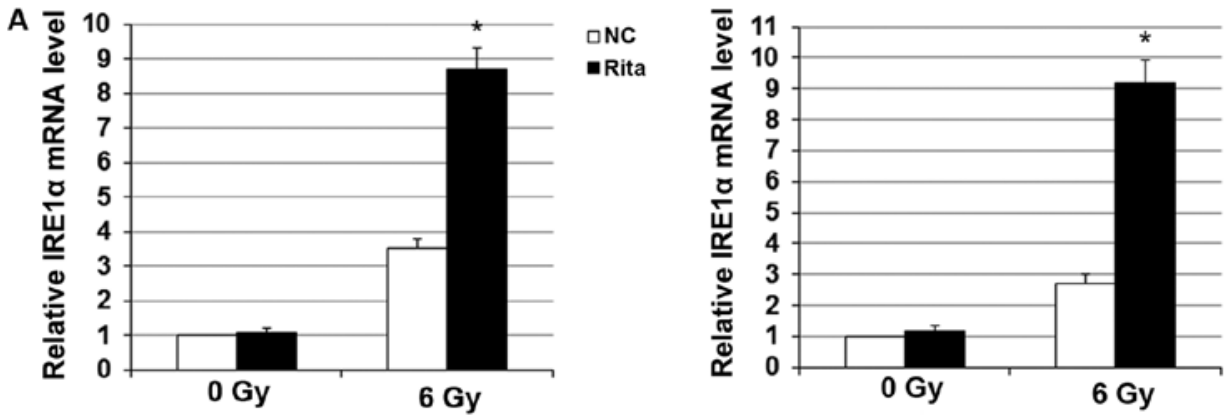

口NC

- Rita
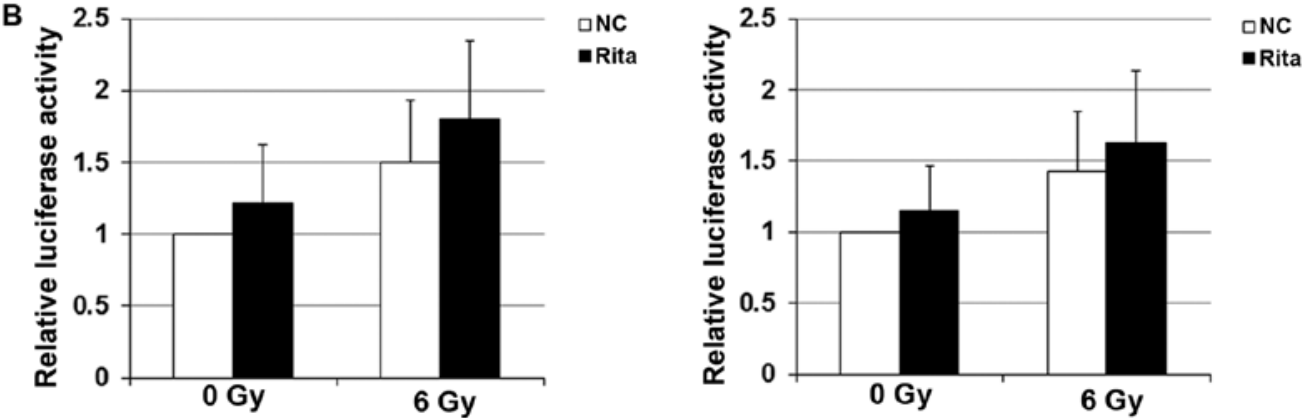

Figure 9. Effects of RITA on IRE1 $\alpha$ mRNA level and promoter activity in cervical cancer cells in the presence or absence of irradiation. (A) C-33A (left panel) and HT-3 cells (right panel) cells were cultured with or without $1 \mu \mathrm{M}$ of RITA for $24 \mathrm{~h}$ before irradiation at 0 (sham irradiation) or $6 \mathrm{~Gy}$ with a linear accelerator operating at $200 \mathrm{cGy} / \mathrm{min}$ and $6 \mathrm{MV}$. The mRNA level of IRE1 $\alpha$ was determined $24 \mathrm{~h}$ after irradiation with real-time reverse transcription PCR assays. (B) C-33A (left panel) and HT-3 (right panel) cells were transfected with human IREl $\alpha$ gene promoter/luciferase reporter plasmids and then cultured with or without $1 \mu \mathrm{M}$ of RITA for $24 \mathrm{~h}$ before irradiation at 0 (sham irradiation) or $6 \mathrm{~Gy}$ with a linear accelerator operating at $200 \mathrm{cGy} / \mathrm{min}$ and $6 \mathrm{MV}$. Twentyfour hours after irradiation, luciferase activities were determined in NC and cells treated with $1 \mu \mathrm{M}$ of RITA for $24 \mathrm{~h}$ before irradiation. The mRNA levels of IRE $1 \alpha$ and the luciferase activities were both expressed as a fold-change to that of $\mathrm{NC}$ at $0 \mathrm{~Gy}$ (designated as 1 ). ${ }^{*} \mathrm{P}<0.05 \mathrm{vs}$. NC. RITA, cells treated with $1 \mu \mathrm{M}$ of RITA for $24 \mathrm{~h}$ before irradiation; NC normal control cells.

A

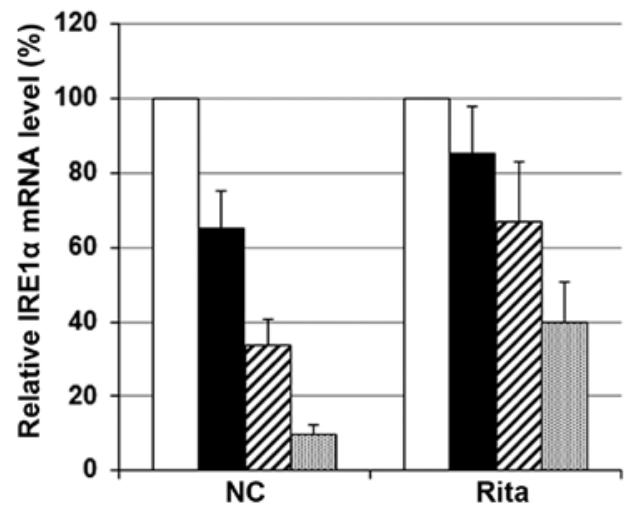

$00 \mathrm{~h}$

$.1 \mathrm{~h}$

$02 \mathrm{~h}$

$\square 4 \mathrm{~h}$

\section{.}

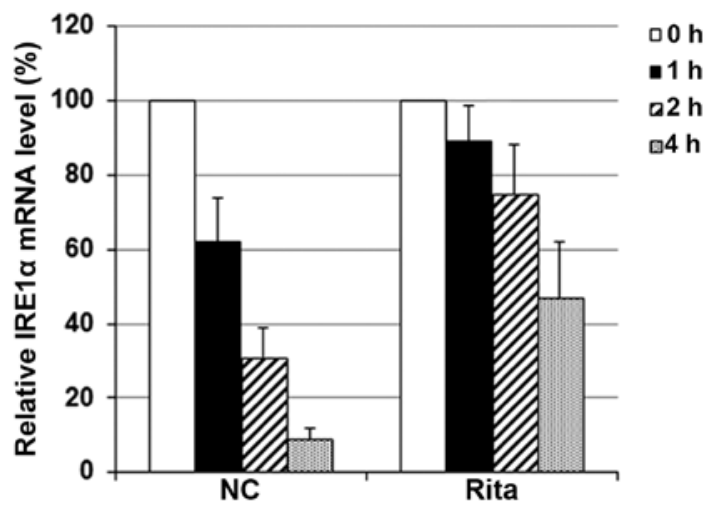

Figure 10. Effects of RITA on IRE1 $\alpha$ mRNA stability in the cervical cancer cells under irradiation. (A) C-33A and (B) HT-3 cells were cultured with or without $1 \mu \mathrm{M}$ of RITA for $24 \mathrm{~h}$ before irradiation at $6 \mathrm{~Gy}$ with a linear accelerator operating at $200 \mathrm{cGy} / \mathrm{min}$ and $6 \mathrm{MV}$. IRE1 $\alpha$ mRNA stability was examined immediately after irradiation by transcriptional pulse-chase assays using a Click-iT Nascent RNA Capture kit. Briefly, the cells were labeled with EU and incubated at $37^{\circ} \mathrm{C}$ for $4 \mathrm{~h}$. Cells were then allowed to recover in EU-free medium for $0,1,2 \mathrm{or} 4 \mathrm{~h}$, respectively. Then the labeled RNA was captured and subject to real-time reverse transcription PCR assays to determine the IRE1 $\alpha$ mRNA levels. The IRE1 $\alpha$ mRNA level at $0 \mathrm{~h}$ was designated as $100 \%$. RITA, cells treated with $1 \mu \mathrm{M}$ of RITA for $24 \mathrm{~h}$ before irradiation; NC normal control cells; EU, ethynyl uridine.

cells (20). However, few studies have explored the effect of RITA on mtp53-expressing cervical cancer cells. Thus, we employed C-33A and HT-3 cells, two human cervical cancer cell lines expressing mtp53, as cell models in the present study $(18,19)$. At the concentration of $1 \mu \mathrm{M}$, RITA markedly enhanced apoptosis in the mtp53-expressing cervical cancer cells under irradiation, but not in those under sham irradiation. The radiosensitivity-enhancing effect of RITA at $1 \mu \mathrm{M}$ was obviously p53-independent, since it was not altered by knockdown of p53. Much higher concentrations were needed for RITA to induce significant apoptosis in the mtp53expressing cervical cancer cells under sham irradiation in the present study (15.6 for C-33A and $18.3 \mu \mathrm{M}$ for HT-3 cells, respectively). Collectively, the findings suggest that RITA is an effective enhancer of radiosensitivity for mtp53-expressing cervical cancer cells and therefore if used in conjunction with radiotherapy, may be potentially beneficial for patients with mtp53-expressing cervical cancer. This is important 
since radiation therapy is the most broadly used treatment for patients with cervical cancer, particularly patients at an advanced stage or those who cannot be cured surgically (2).

ER stress induced by protein misfolding is an important mechanism in cellular stress (23). ER stress triggers the UPR to restore normal ER functioning (6). The UPR is mediated by three principal classes of stress sensors including PERK, ATF6 and IRE1 (8), which operate in parallel and use unique mechanisms of signal transduction to orchestrate adaptation to ER stress $(5,8)$. However, if UPR is insufficient to reverse the ER stress or recover ER homeostasis, the cell fate switches to apoptosis (5). Recent studies have shown that ER stress induces apoptosis and sensitizes tumor cells to ionizing radiation (10-12), suggesting that ER stress has the potential as a novel target to improve cancer radiotherapy, which reportedly induces cellular ER stress (13). In the present study, irradiation led to irreversible ER stress in the C-33A and HT-3 cells, as indicated by the significantly increased IRE1 $\alpha / \mathrm{XBP} 1 \mathrm{ER}$ stress signaling and apoptosis in the irradiated cells compared with that in the sham-irradiated cells. RITA markedly enhanced IRE1 $\alpha / \mathrm{XBP} 1$ signaling and apoptosis in the irradiated C-33A and HT-3 cells, suggesting that RITA enhanced apoptosis in irradiated mtp53-expressing cervical cancer cells by enhancing irradiation-induced ER stress, mainly through the IRE1 $\alpha / \mathrm{XBP} 1$ signaling pathway. Knockdown of p53 did not alter this effect of RITA, confirming that it was through a p53-independent mechanism. Some previous studies have shown that ER stress sensitizes or stimulates wtp53-dependent apoptosis $(24,25)$, while others have shown that ER stress prevents or inhibits wtp53-dependent apoptosis (26-29). The discrepancies can be attributed to different cell models or treatments/stimuli used in the studies. Nevertheless, since RITA is an established activator of p53, it may be intriguing to determine whether and how RITA may affect radiosensitivity and apoptosis in irradiated wtp53-expressing cervical cancer cells. We will focus on these issues in future studies.

We found that RITA increased the expression of IRE1 $\alpha$ in the irradiated C-33A and HT-3 cells at both the protein and the mRNA levels. Transcriptional pulse-chase assays immediately after irradiation revealed that treatment with $1 \mu \mathrm{M}$ of RITA for $24 \mathrm{~h}$ before irradiation significantly increased the stability of IRE1 $\alpha$ mRNA. This effect was manifested at the IRE1 $\alpha$ protein level, spliced XBP1 mRNA level and the cell apoptosis level $24 \mathrm{~h}$ after irradiation, confirming RITA as an effective and efficient enhancer of irradiation-induced ER stress/apoptosis in mtp53-expressing cervical cancer cells. The mechanism of how RITA increases IRE1 $\alpha$ mRNA stability in irradiated mtp53-expressing cervical cancer cells is still unclear and will be explored in our future studies.

Our findings suggest that RITA may be useful as an enhancer of radiosensitivity for mtp53-expressing cancer cells. Since approximately half of all human cancers harbor mutations in p53 (15) and we only tested mtp53-expressing cervical cancer cell models in the present study, it would be beneficial to ascertain whether RITA can enhance irradiation-induced ER stress and apoptosis in other irradiation-sensitive cancers harboring mtp53. Moreover, as certain chemotherapeutic agents reportedly induce tumor cell apoptosis mainly through stimulation of ER stress, it may also be beneficial to discover whether RITA can enhance chemotherapeutic agent-induced
ER stress/apoptosis in cancers harboring mtp53. Furthermore, PERK, ATF6 and IRE1 represent three branches of the $\operatorname{UPR}(5,8)$. We found in the present study that RITA is mainly affected through the IRE1 branch of UPR. Whether the PERK and the ATF6 branches of UPR could be critically involved in the potential effects of RITA on irradiation- or chemotherapeutic agent-induced ER stress/apoptosis in other types of mtp53-expressing cancers still needs to be elucidated in future studies.

In conclusion, the present study provides initial evidence that RITA upregulates the expression level of IRE1 $\alpha$ by increasing the stability of IRE $1 \alpha$ mRNA in irradiated mtp53-expressing cervical cancer cells; the effect leads to enhanced IRE1 $\alpha /$ XBP1 ER stress signaling and increased apoptosis in the cells. The present study offers novel insight into the pharmacological potential of RITA in the radiotherapy for cervical cancer.

\section{Acknowledgements}

The present study was supported by the National Natural Science Foundation of China (grant no. 81372428), the Natural Science Foundation of Hunan Province (grant no. 11JJ5080), and the Science and Technology Plan Fund of Hunan Province (grant nos. 2010RS4031 and 2011FJ3028), China.

\section{References}

1. Ferlay J, Shin HR, Bray F, Forman D, Mathers C and Parkin DM: Estimates of worldwide burden of cancer in 2008 : GLOBOCAN 2008. Int J Cancer 127: 2893-2917, 2010.

2. Dalerba P, Cho RW and Clarke MF: Cancer stem cells: Models and concepts. Annu Rev Med 58: 267-284, 2007.

3. Hu Q and Hill RP: Radiosensitivity, apoptosis and repair of DNA double-strand breaks in radiation-sensitive Chinese hamster ovary cell mutants treated at different dose rates. Radiat Res 146: 636-645, 1996

4. Xiang L, Xie G, Liu C, Zhou J, Chen J, Yu S, Li J, Pang X, Shi H and Liang H: Knock-down of glutaminase 2 expression decreases glutathione, NADH, and sensitizes cervical cancer to ionizing radiation. Biochim Biophys Acta 1833: 2996-3005, 2013.

5. Walter P and Ron D: The unfolded protein response: From stress pathway to homeostatic regulation. Science 334: 1081-1086, 2011.

6. Schröder M and Kaufman RJ: The mammalian unfolded protein response. Annu Rev Biochem 74: 739-789, 2005.

7. Hetz C, Martinon F, Rodriguez D and Glimcher LH: The unfolded protein response: Integrating stress signals through the stress sensor IRE1 $\alpha$. Physiol Rev 91: 1219-1243, 2011.

8. Ron D and Walter P: Signal integration in the endoplasmic reticulum unfolded protein response. Nat Rev Mol Cell Biol 8: 519-529, 2007.

9. Yoshida H, Matsui T, Yamamoto A, Okada T and Mori K: XBP1 mRNA is induced by ATF6 and spliced by IRE1 in response to ER stress to produce a highly active transcription factor. Cell 107: 881-891, 2001.

10. Yamamori T, Meike S, Nagane M, Yasui H and Inanami O: ER stress suppresses DNA double-strand break repair and sensitizes tumor cells to ionizing radiation by stimulating proteasomal degradation of Rad51. FEBS Lett 587: 3348-3353, 2013.

11. Johnson GG, White MC and Grimaldi M: Stressed to death: Targeting endoplasmic reticulum stress response induced apoptosis in gliomas. Curr Pharm Des 17: 284-292, 2011.

12. Huang HJ, Lin CC, Chou HC, Chen YW, Lin ST, Lin YC, Lin DY, Lyu KW and Chan HL: Proteomic analysis of rhein-induced cyt: ER stress mediates cell death in breast cancer cells. Mol Biosyst 10: 3086-3100, 2014.

13. Saglar E, Unlu S, Babalioglu I, Gokce SC and Mergen H: Assessment of ER stress and autophagy induced by ionizing radiation in both radiotherapy patients and ex vivo irradiated samples. J Biochem Mol Toxicol 28: 413-417, 2014. 
14. El-Deiry WS: The role of $\mathrm{p} 53$ in chemosensitivity and radiosensitivity. Oncogene 22: 7486-7495, 2003.

15. Weilbacher A, Gutekunst M, Oren M, Aulitzky WE and van der Kuip H: RITA can induce cell death in p53-defective cells independently of p53 function via activation of JNK/SAPK and p38. Cell Death Dis 5: e1318, 2014.

16. Issaeva N, Bozko P, Enge M, Protopopova M, Verhoef LG, Masucci M, Pramanik A and Selivanova G: Small molecule RITA binds to p53, blocks p53-HDM-2 interaction and activates p53 function in tumors. Nat Med 10: 1321-1328, 2004

17. Chuang HC, Yang LP, Fitzgerald AL, Osman A, Woo SH, Myers JN and Skinner HD: The p53-reactivating small molecule RITA induces senescence in head and neck cancer cells. PLoS One 9: e104821, 2014.

18. Yaginuma $\mathrm{Y}$ and Westphal $\mathrm{H}$ : Analysis of the $\mathrm{p} 53$ gene in human uterine carcinoma cell lines. Cancer Res 51: 6506-6509, 1991.

19. Srivastava S, Tong YA, Devadas K, Zou ZQ, Chen Y, Pirollo KF and Chang EH: The status of the p53 gene in human papilloma virus positive or negative cervical carcinoma cell lines. Carcinogenesis 13: 1273-1275, 1992

20. Zhao CY, Szekely L, Bao W and Selivanova G: Rescue of p53 function by small-molecule RITA in cervical carcinoma by blocking E6-mediated degradation. Cancer Res 70: 3372-3381, 2010.

21. Byun K, Bayarsaikhan E, Kim D, Kim CY, Mook-Jung I, Paek SH Kim SU, Yamamoto T, Won MH, Song BJ, et al: Induction of neuronal death by microglial AGE-albumin: Implications for Alzheimer's disease. PLoS One 7: e37917, 2012.

22. Zhao CY, Grinkevich VV, Nikulenkov F, Bao W and Selivanova G: Rescue of the apoptotic-inducing function of mutant p53 by small molecule RITA. Cell Cycle 9: 1847-1855, 2010.
23. van Schadewijk A, van't Wout EF, Stolk J and Hiemstra PS: A quantitative method for detection of spliced X-box binding protein-1 (XBP1) mRNA as a measure of endoplasmic reticulum (ER) stress. Cell Stress Chaperones 17: 275-279, 2012.

24. Lin WC, Chuang YC, Chang YS, Lai MD, Teng YN, Su IJ, Wang CC, Lee KH and Hung JH: Endoplasmic reticulum stress stimulates p53 expression through NF- $\mathrm{BB}$ activation. PLoS One 7: e39120, 2012

25. Mlynarczyk C and Fåhraeus R: Endoplasmic reticulum stress sensitizes cells to DNA damage-induced apoptosis through p53-dependent suppression of p21(CDKN1A). Nat Commun 5: 5067, 2014.

26. Qu L, Huang S, Baltzis D, Rivas-Estilla AM, Pluquet O, Hatzoglou M, Koumenis C, Taya Y, Yoshimura A and Koromilas AE: Endoplasmic reticulum stress induces p53 cytoplasmic localization and prevents $\mathrm{p} 53$-dependent apoptosis by a pathway involving glycogen synthase kinase-3beta. Genes Dev 18: 261-277, 2004.

27. Pluquet O, Qu LK, Baltzis D and Koromilas AE: Endoplasmic reticulum stress accelerates p53 degradation by the cooperative actions of Hdm2 and glycogen synthase kinase 3beta. Mol Cell Biol 25: 9392-9405, 2005.

28. Pan JM, Zhou L, Wang GB, Xia GW, Xue K, Cui XG, Shi HZ, Liu JH and $\mathrm{Hu}$ J: Fatsioside A inhibits the growth of glioma cells via the induction of endoplasmic reticulum stress-mediated apoptosis. Mol Med Rep 11: 3493-3498, 2015.

29. Chiu HW, Tseng YC, Hsu YH, Lin YF, Foo NP, Guo HR and Wang YJ: Arsenic trioxide induces programmed cell death through stimulation of ER stress and inhibition of the ubiquitinproteasome system in human sarcoma cells. Cancer Lett 356: 762-772, 2015. 